\title{
Mechanical Behavior of Polymer Composites Reinforced with Coir and Date Palm Frond Fibers
}

\author{
Tabassum Sadik, ${ }^{1}$ S. Muthuraman, ${ }^{1}$ M. Sivaraj $\mathbb{D}^{2}{ }^{2}$ Kassu Negash $\mathbb{D}^{2},{ }^{2}$ R. Balamurugan, ${ }^{3}$ \\ and S. Bakthavatsalam ${ }^{4}$ \\ ${ }^{1}$ University of Technology and Applied Sciences, HCT, Muscat, Oman \\ ${ }^{2}$ Department of Mechanical Engineering, Faculty of Manufacturing, Institute of Technology, Hawassa University, \\ Hawassa, Ethiopia \\ ${ }^{3}$ Mechanical Engineering, M.Kumarasamy College of Engineering, Karur, India \\ ${ }^{4}$ Department of Physics, K.Ramakrishnan College of Engineering, Samayapuram, Trichy 621112, Tamilnadu, India
}

Correspondence should be addressed to M. Sivaraj; msivaraj2014@gmail.com

Received 27 November 2021; Accepted 17 December 2021; Published 17 January 2022

Academic Editor: Antonio Caggiano

Copyright (c) 2022 Tabassum Sadik et al. This is an open access article distributed under the Creative Commons Attribution License, which permits unrestricted use, distribution, and reproduction in any medium, provided the original work is properly cited.

\begin{abstract}
This article explains to study the feasibility of natural fiber (date palm frond and coir fibers from Oman) reinforced polymer composite laminates processed using the hand lay method. Untreated and alkali-treated fiber composite laminate specimens of longitudinal and transverse direction fibers were subjected to various mechanical property tests (such as tensile, flexural, compression, shear, and hardness). Results show that the required polymer composite is ecofriendly, has no harm by natural fiber composite, and enhances mechanical strength and low density with specific strength. Hence, it is suitable for industrial and structural applications due to its improved mechanical properties.
\end{abstract}

\section{Introduction}

1.1. Overview of Composites. Composites are being made for several thousand years; mud brick is an example of a composite. It has good compressive strength, so it is hard to be squashed. However, it breaks quite easily when it is attempted to bend which means it has low tensile strength. Composite materials are a combination of matrix and reinforcement materials in order to get the properties of combined materials. Generally, composites have two main materials which are reinforcement materials (discontinues) and matrix or base (continues material).

In this research, two types of composite laminates were processed using polyester resin as a matrix and plant leaf frond fibers of date palm with glass fiber and from fruit fibers Coir with glass fiber as a hybrid reinforcement material (Figures 1 and 2) [1,2]. Moreover, this type of composite is called hybrid natural fiber composite; hybrid means using two or more reinforcement materials in the composite.
Furthermore, we are going to study the behavior of those composites and how they respond to mechanical test, chemical test, thermal conductivity test, and electrical conductivity test.

As natural fibers have several benefits such as easy availability, biodegradability, lightweight, low cost, and ease of manufacturing, natural fiber-based biocomposites have replaced synthetic plastics in a wide variety of fields $[3,4]$. Several researchers have proposed many natural fiber-based composites for various engineering applications [5]. Because of their lightweight nature, biocomposites used by the automobile industries enhance their fuel economy [6]. Researchers have also investigated hybrid biocomposites that are made by adding two or more varieties of natural fibers in a standard matrix to increase the mechanical properties [7].

Neher et al. [8] investigated the mechanical and physical properties of the palm fiber reinforced acrylonitrile butadiene styrene composite. The mechanical properties of palmyra fruit fiber and palmyra fiber waste-filled redmud 

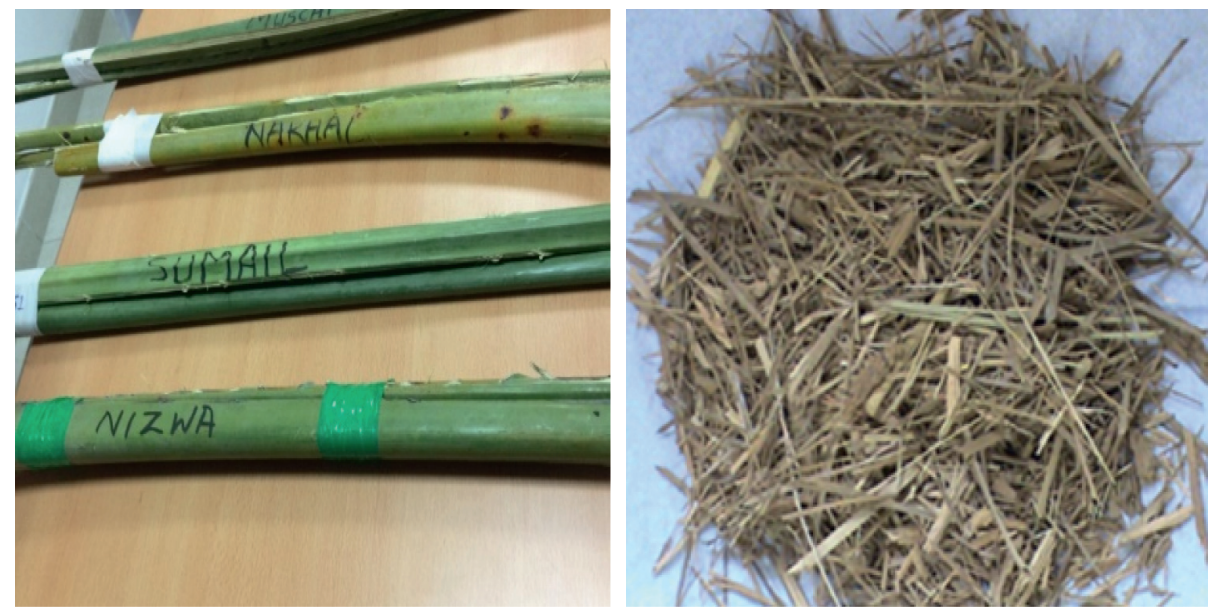

Figure 1: Date palm fibers.
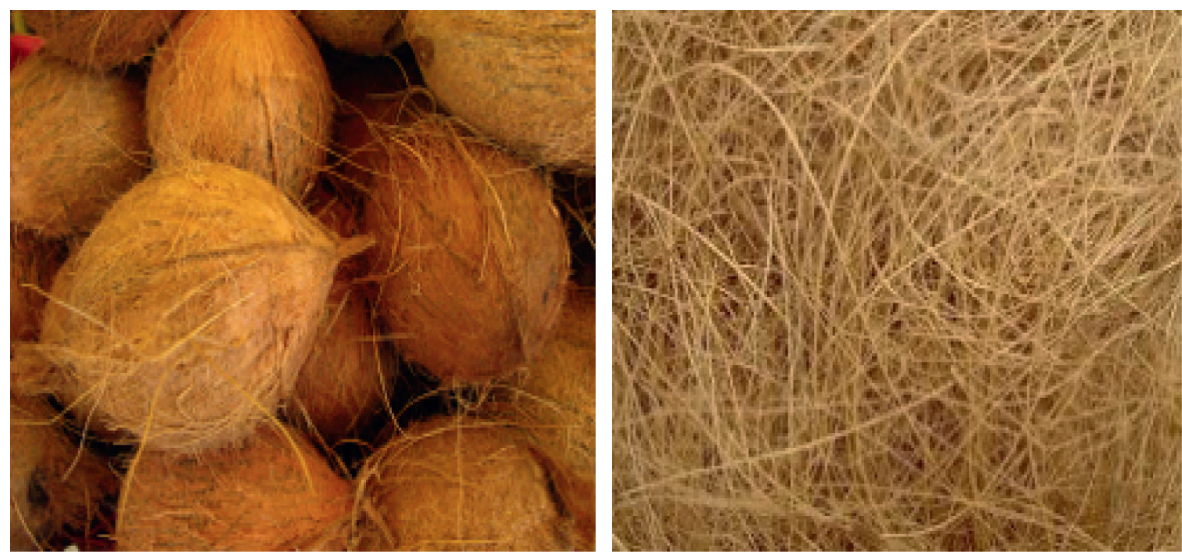

Figure 2: Coir fibers.

were studied by Arumuga Prabu et al. [9]. The outcome of surface treatment on the physical, chemical, and mechanical properties of palm tree leaf stalk fibers was addressed by Rout et al. [10]. The bio-based composite from rice husk epoxy resin could impedingly substitute the conventional synthetic fiber reinforced epoxy composites in PCB applications. The essential properties of biocomposites were assessed such as tensile and bending properties, dielectric properties, thermal properties, moisture absorption, microdrilling, biodegradability, and flammability [11]. The dynamic mechanical analysis of fabricated composites has been carried out to determine the storage modulus, glass transition temperature, and activation energy. The effect of stress and temperature on the creep and recovery behavior of cross-linked PVA and basalt fiber reinforced composite are studied, and the burger model is used to study the creep data [12].

1.2. General Characteristics of Natural Fibers and Fiber-Glass Composites. The properties of each natural fiber composite are not the same as another because of different types of natural fibers, sources, and moisture conditions. The effectiveness and performance of natural fiber polymer composites depend on some main roles such as mechanical composition, microfibular angle, structure of the composite, and interaction of reinforcement material with the matrix. The natural fiber polymer composite has some disadvantages in life. These drawbacks are taken into account by the mixture of natural fibers and the glass fiber matrix owing to the difference in the chemical structure between the two phases. Also, the effectiveness is reliant upon the interface provided by the matrix along with a load transfer role from the matrix. The mechanical properties of the natural fiber composites are able to be developed and enhanced by a suggestion for the natural fibers that can be employed in order to improve their mechanical properties. To increase their performance level, some arrangements should be taken into consideration:
(1) Orientation of fibers
(2) Fiber strength
(3) Physical properties of a fiber
(4) An interfacial bonding property of fibers

1.3. Project Objectives. The purpose of this research is to identify whether DPF and coir natural fibers with glass fiber 
reinforced composites are potentially economic, environmental, and mechanical performance substitutes for conventional materials such as polymers, wood, and a few metals. It specifically addresses if the renewable fibers especially date palm fibers (DPF) which are biodegradable, abundantly available as waste materials reinforced with fiber-glass composites, are competitive with the incumbent with low load low-bearing materials; then, potential applications range from automobile parts and construction interiors to small consumer products.

(1) The utilization of renewable natural fibers (DPF and coir) into engineering applications.

(2) To find the potential and effects of fibers by varying alkali treatment $(0 \%, 5 \%$, and $10 \%)$ and used as reinforcement with glass fiber composites for different compositions. Investigating their mechanical, physical, and thermal properties.

(3) Preparation of different compositions (10\%, 20\%, and $30 \% \mathrm{wt}$ ratios) of natural fibers with glass fiber hybrid reinforced polymer composite materials by the hand lay method.

(4) Evaluation of various mechanical properties such as tensile, bending, compression, shear, and hardness tests.

(5) Evaluating principal normal stresses and various failure theories.

(6) Preparation of model sample products for an application based on the above test results.

\section{Materials and Methods}

This section describes the detail of processing of a composite using the design of experiment by the Taguchi method. The raw materials used in this work are as follows.

\subsection{Materials}

(1) Fiber glass chopped mat

(2) Natural fibers (date palm fronds and coconut coir)

(3) Polyester resin (L-12)

(4) Hardener (K-6)

(5) $\mathrm{NaOH}$ solution

2.1.1. Fiber Glass Mat. Fiber glass chopped mat (350 grade) gives comfort handling easy to use it at any molds, is economical, has steady dimension, has good mechanical properties, resists chemicals, and is a good conductor of electricity, supplied by Suntech Fibre Private Limited, Bangalore, India.

(i) The density of it is $1.22 \mathrm{~g} / \mathrm{cc}$

(ii) Strength $70 \mathrm{MPa}$

(iii) Easy to tailor physical properties

(iv) The composite can be used for different applications because of its excellent surface quality making the water boats, automobile panels look good, etc.
2.1.2. Natural Fibers: DPF and Coir Fibers. Natural fibers are a renewable resource found abundantly as a waste material. These fibers contain high specific strength and rigidity, have a desirable fiber aspect ratio, and are biodegradable. Date palm fronds (DPF) were collected from the Nizwa region belonging to the family of Khalas date palm tree. From the previous project study, these fibers were found with high strength from test results. Coir fibers were collected from the supermarkets in Muscat. Single fibers were extracted, cleaned, and then tested; the results are given in Table 1.

2.1.3. Polyester Resin (L-12). Features of polyester resin are as follows:

(i) Low cost and easy to get

(ii) Solidifies faster than epoxy

(iii) Makes more attractive than some higher performance resins such as epoxy

(iv) Ability accepts board verity fillers which make it having wide usage applications

2.1.4. Hardener (K-6). Hardener may be a natural action agent for epoxy or covering material. The synthetic resin needs a hardener to initiate curing; additionally known as the catalyst, the substance hardens the adhesive once mixed with an organic compound. It is the particular choice and combination of the epoxy and hardener parts that verify the ultimate characteristics and quality of the epoxy coating for a given atmosphere.

2.1.5. $\mathrm{NaOH}$. The fibers are treated by using the alkali treatment method with sodium hydroxide $(\mathrm{NaOH})$ with distilled water $[13,14]$. The reason for treating fibers is to remove the moisture content from the fibers, thereby increasing their strength. Moreover, it enhances the flexural rigidity of the fibers. It increases the roughness of the surface by disrupting the connection of hydrogen to the network structure. Certain quantities of lignin, wax, and oils that cover the external fiber cell wall are removed by alkaline treatment.

\subsection{Methods}

\subsubsection{Extraction of Fibers (Figure 3)}

(1) Date palm.

(i) Date palm fronds (scientific name is "Phoenix Dactylifera")

(ii) Date palm is a flowering plant species in the palm family

(iii) It is mostly found in the Middle East, Pakistan, India, and the U.S state of California

(iv) Fibers were extracted by using the mechanical rolling machine, cleaned with distilled water, and dried in an electric oven at $103^{\circ} \mathrm{C}$ for 2 to $3 \mathrm{~h}$

(v) Few quantities of these fibers were treated with 5\% and $10 \% \mathrm{NaOH}$ 
TABLE 1: Mechanical properties of natural fibers.

\begin{tabular}{lccc}
\hline & DPF single fibers & & \\
\hline $\mathrm{NaOH}$ & $0 \%$ & $5 \%$ & $10 \%$ \\
$\mathrm{Max}$ stress (MPa) & 81.8 & 45.95 & 17.89 \\
Elongation \% & 0.75 & 0.88 & 0.75 \\
Young's modulus (GPa) & 4.69 & 5.96 & 3.96 \\
Density (g/cc) & 0.464 & 0.412 & 0.358 \\
\hline & Coir single fibers & \\
\hline $\mathrm{NaOH}$ & $0 \%$ & $5 \%$ & $10 \%$ \\
$\mathrm{Max}$ stress (MPa) & 209.15 & 232.30 & 240.60 \\
Elongation \% & 14.95 & 9.36 & 7.05 \\
Young's modulus (GPa) & 5.352 & 5.17 & 3.407 \\
Density (g/cc) & 0.699 & 0.665 & 0.606 \\
\hline
\end{tabular}
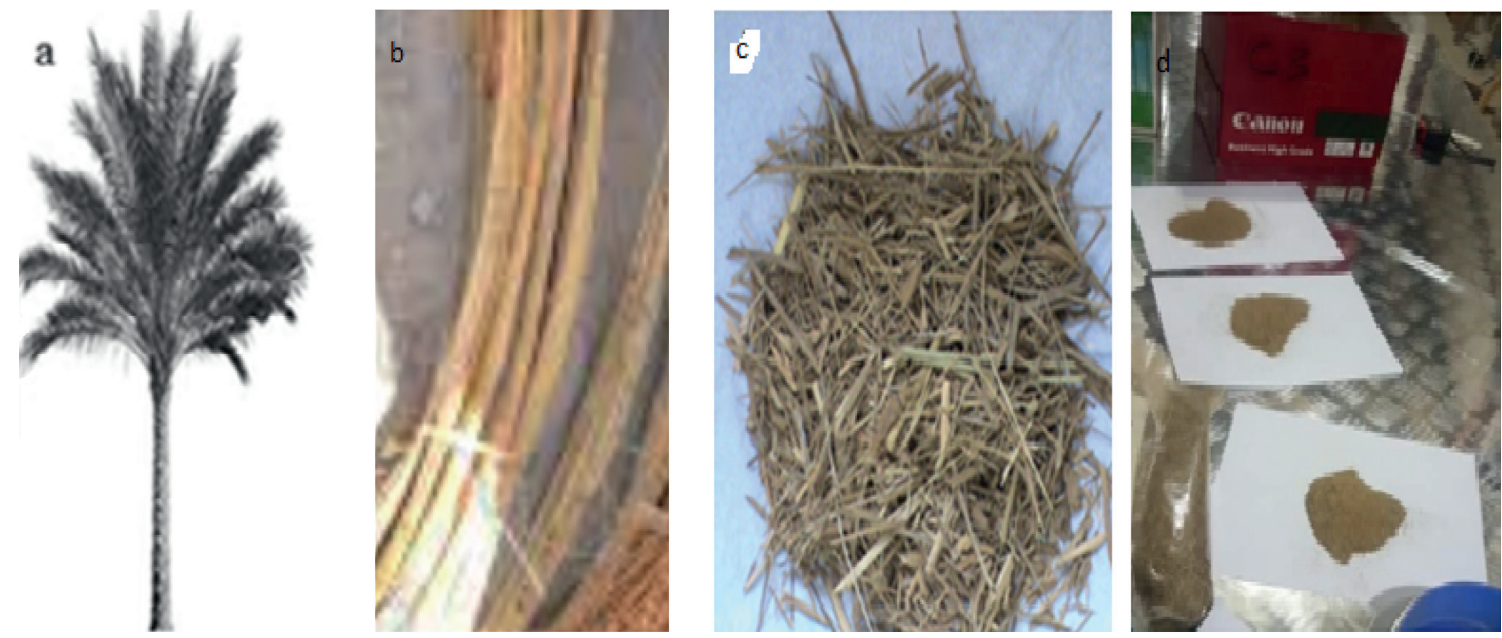

Figure 3: Extraction of date palm frond (DPF) fibers.

(vi) Untreated and treated fibers were grinded and sieved to obtain $0.7 \mathrm{~mm}$ diameter short fibers

(2) Coconut Coir (Figure 4).

(i) The coconut tree is a member of the palm tree family

(ii) It is also known by its scientific name as "Cocos Nucifera"

(iii) Countries with highest coconut trees are Indonesia, the Philippines, India, and Brazil

(iv) Fibers were extracted manually, cleaned with distilled water, and dried in an electric oven at $103^{\circ} \mathrm{C}$ for 2 to $3 \mathrm{~h}$

(v) Few quantities of these fibers were treated with 5\% and $10 \% \mathrm{NaOH}$

(vi) Untreated and treated fibers were grinded and sieved to obtain $0.7 \mathrm{~mm}$ diameter short fibers
2.2.2. Alkali Treatment of Fibers. Freshly drawn fibers usually contain many specks of dust that can have a negative impact bonding the fiber matrix. The composite material produced from such fibers may not have adequate mechanical properties. Fibers are cleaned in clean running water and distilled water and then dried. A glass beaker is taken; $5 \%$ and $10 \% \mathrm{NaOH}$ is added; $95 \%$ and $90 \%$ distilled water is added; a solution is prepared; fibers were soaked into the solution for $6 \mathrm{~h}$. Fibers were washed with distilled water to remove the excess solution from the surface of it. After adequate cleaning, it is dried using an electric oven for 2 to $3 \mathrm{~h}$. This chemical treatment for fibers is to remove dust and layer lignin to increase surface roughness to enhance its mechanical properties.

According to the rule of mixture, the properties of composite materials are estimated as follows: density and mass of polymer composite laminate (refer Tables 2and 3). 

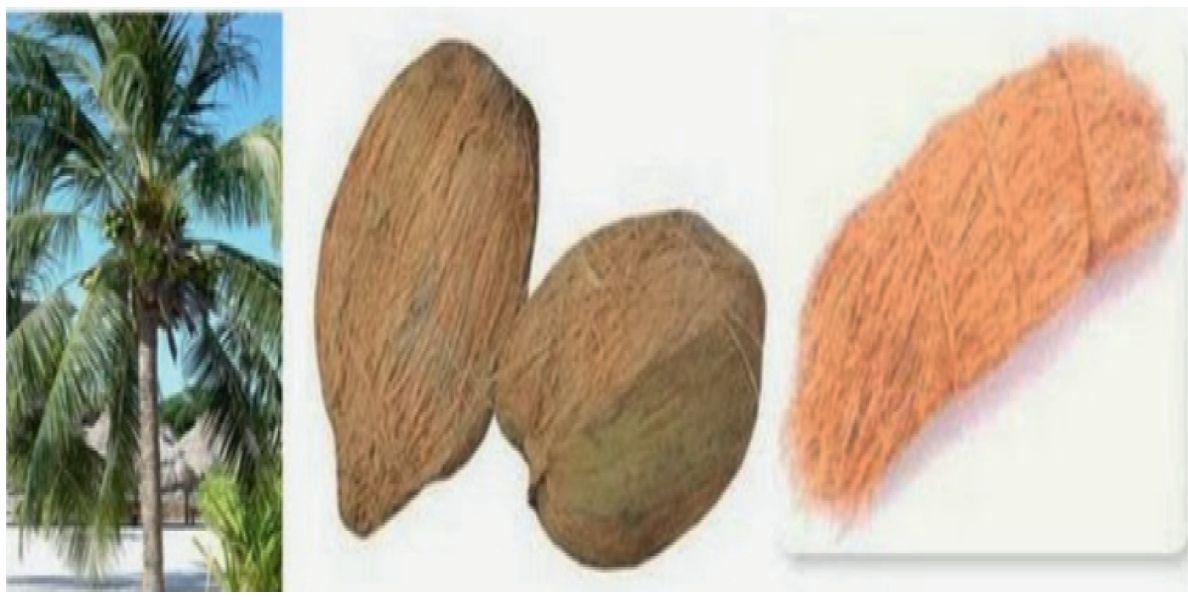

Figure 4: Coconut coir fibers.

TABLE 2: Estimated density and mass of DPF fiber reinforced composite using the rule of mixture.

DPF composite

\begin{tabular}{cccccc} 
Wt. ratio (\%) & $\mathrm{NaOH}$ treatment (\%) & Notations & Mass of composite $(g m s)$ & Theoretical density $(g / c c)$ & Experimental density $(g / c c)$ \\
\hline \multirow{3}{*}{10} & 0 & DPF1 & 546.6 & 1.04 & 1.11 \\
& 5 & DPF2 & 483.14 & 0.968 & 0.973 \\
20 & 10 & DPF3 & 478.78 & 0.977 & 0.95 \\
& 0 & DPF4 & 476.86 & 1.01 & 1.1 \\
30 & 5 & DPF5 & 405.5 & 0.876 & 0.946 \\
& 10 & DPF6 & 399.2 & 0.814 & 0.878 \\
\hline
\end{tabular}

TABLE 3: Estimated density and mass of coir fiber reinforced composite using the rule of mixture.

(\%) Coir composite

Wt ratio (\%) $\mathrm{NaOH}$ treatment (\%) Notations $\quad$ Mass of composite (gms) Theoretical density (g/cc) Experimental density (g/cc)

\begin{tabular}{|c|c|c|c|c|c|}
\hline \multirow{3}{*}{10} & 0 & $\mathrm{CC} 1$ & 555.5 & 1.13 & 1.04 \\
\hline & 5 & CC2 & 518.2 & 1.05 & 0.91 \\
\hline & 10 & $\mathrm{CC} 3$ & 485.8 & 0.99 & 0.81 \\
\hline \multirow{3}{*}{20} & 0 & $\mathrm{CC} 4$ & 551.7 & 1.11 & 1.02 \\
\hline & 5 & CC5 & 512.8 & 1.03 & 0.87 \\
\hline & 10 & CC6 & 478 & 0.95 & 0.77 \\
\hline \multirow{3}{*}{30} & 0 & CC7 & 510.4 & 1.1 & 1.0 \\
\hline & 5 & CC8 & 444.5 & 1.01 & 0.85 \\
\hline & 10 & СС9 & 395 & 0.93 & 0.74 \\
\hline
\end{tabular}


TABLE 4: ASTM standard specimen dimensions.

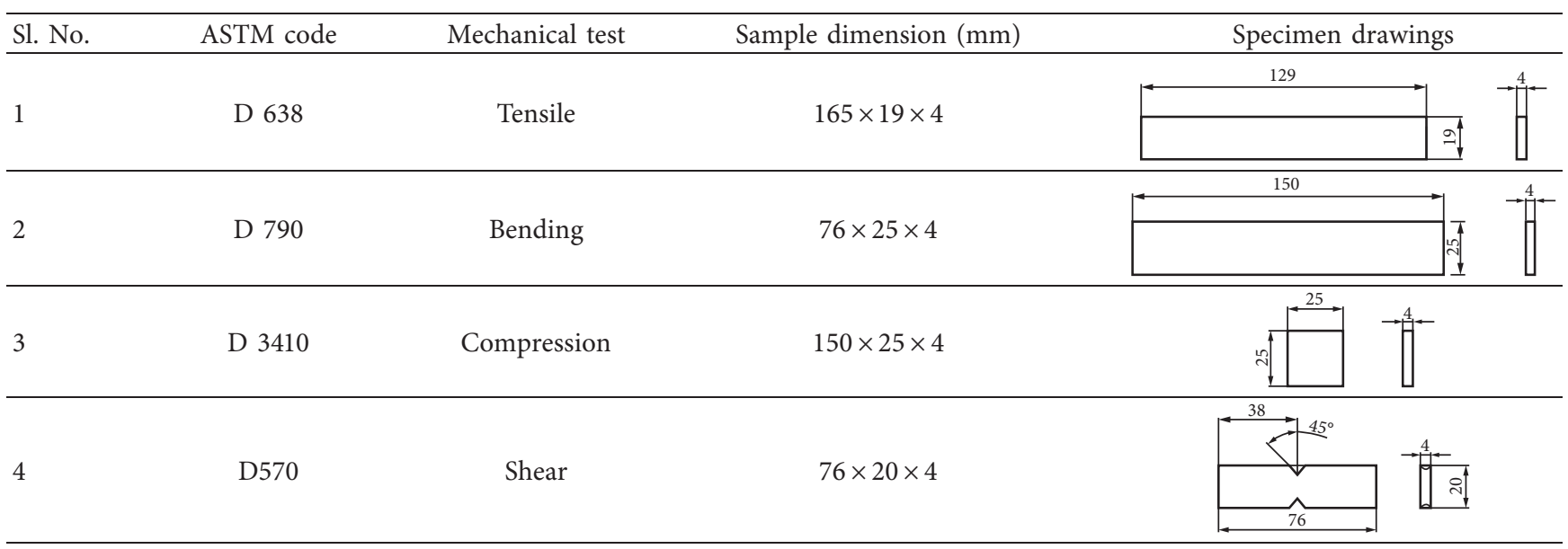

$$
\begin{aligned}
V_{c} & =V_{p}+V_{\mathrm{DPF}}, \\
V_{c} & =\frac{m_{c}}{\rho_{c}}=\frac{m_{m}}{\rho_{m}}+\frac{m_{\mathrm{DPF}}}{\rho_{\mathrm{DPF}}}, \\
\frac{1}{\rho_{c}} & =\left(\frac{m_{m}}{\rho_{m} \times m_{c}}\right)+\left(\frac{m_{\mathrm{DPF}}}{\rho_{\mathrm{DPF}} \times m_{c}}\right) \text { for DPF fiber } 5 \% \mathrm{NaOH}, \\
\frac{1}{\rho_{c}} & =\left(\frac{0.9}{1.22 \times 1}\right)+\left(\frac{0.1}{0.362 \times 1}\right), \\
\rho_{c} & =0.986 \mathrm{~g} / \mathrm{cc}, \\
V_{c} & =l \times w \times t, \text { composite laminates dimensions, } \\
V_{c} & =35 \times 35 \times 0.4=490 \mathrm{~cm}^{3}(\text { mold dimensions }), \\
m_{c} & =\rho_{c} \times V_{c}, \\
m_{c} & =0.986 \times 490=483.14 \text { gram },, \\
m_{D P F} & =483.14 \times 10 \%=48.314 \text { gram } \\
m_{m} & =483.14 \times 90 \%=434.14 \text { gram } .
\end{aligned}
$$

2.2.3. Processing of Composites by the Hand Lay-Up Technique. Hand lay technique is the easiest method to make composites. The infrastructural requirement for this method is minimal. The resin should be mixed with the hardener. Mane while release gel should be applied on the top and bottom sides of molds; then, with help of a painting brush, the resin is applied on the mold; then, the polymer is placed and rolled with roller gently until stuck completely on the mold; after that with help of sieve, natural fibers are distributed randomly; the resin is also distributed randomly with the help of a brush; the polymer is added and rolled; and resin is applied and rolled and the mold is locked. These steps are for one layer, and the same steps are applied for $n$ number of layers.

2.2.4. Specimen Preparation as per ASTM Standards. The samples are cut to the following dimensions as per ASTM standards, as shown in the table below.

\section{Result and Discussion}

3.1. Tensile Test of Composite Specimen. Tensile test specimens from the laminates were prepared as per the ASTM D638 standard, as shown in Tables 4 and 5 for testing the tensile properties such as tensile strength, tensile modulus, $\%$ elongation, and the failure strain of rectangular cross section of the specimen. Four to five specimens for longitudinal and transverse direction of the fibers for all composition of composites were tested at a room temperature $23^{\circ} \mathrm{C} \pm 2$ with a controlled room humidity. The tensile test was performed at a speed of $10 \mathrm{~mm} / \mathrm{min}$ using the $\mathrm{H} 25 \mathrm{KT}$-universal testing machine, as shown in Figures 5-7. Average values of the results were recorded and are shown in Table 6.

3.2. Flexural, Compression, and Shear Tests of Composite Specimen. All the above test specimens from the laminates were prepared as per ASTM D790, D3410, and D570 standards, as shown in Table 7 for testing the flexural properties such as bending strength, maximum deflection, and compression stress; the shear stress of rectangular cross section of the specimen was carried out. Four to five specimens for longitudinal and transverse direction of the fibers for all composition of composites were tested at a room temperature $23^{\circ} \mathrm{C} \pm 2$ with a controlled room humidity. Bending, compression, and shear test were conducted using the H20KT-universal testing machine, as shown in Figures 8-10. The average values for flexural, compression, and shear are recorded in Tables 8-10. 
TABLE 5: Moisture absorption\% results for DPF/coir fiber omposites.

\begin{tabular}{lc}
\hline Notation & Water absorption \% \\
\hline DPFC1 & 0.13 \\
DPFC2 & 0.12 \\
DPFC3 & 0.1 \\
DPFC4 & 0.09 \\
DPFC5 & 0.09 \\
DPFC6 & 0.1 \\
DPFC7 & 0.14 \\
DPFC8 & 0.11 \\
DPFC9 & 0.09 \\
CC1 & 0.04 \\
CC2 & 0.12 \\
CC3 & 0.08 \\
CC4 & 0.08 \\
CC5 & 0.06 \\
CC6 & 0.14 \\
CC7 & 0.14 \\
CC8 & 0.11 \\
CC9 & 0.08 \\
\hline
\end{tabular}
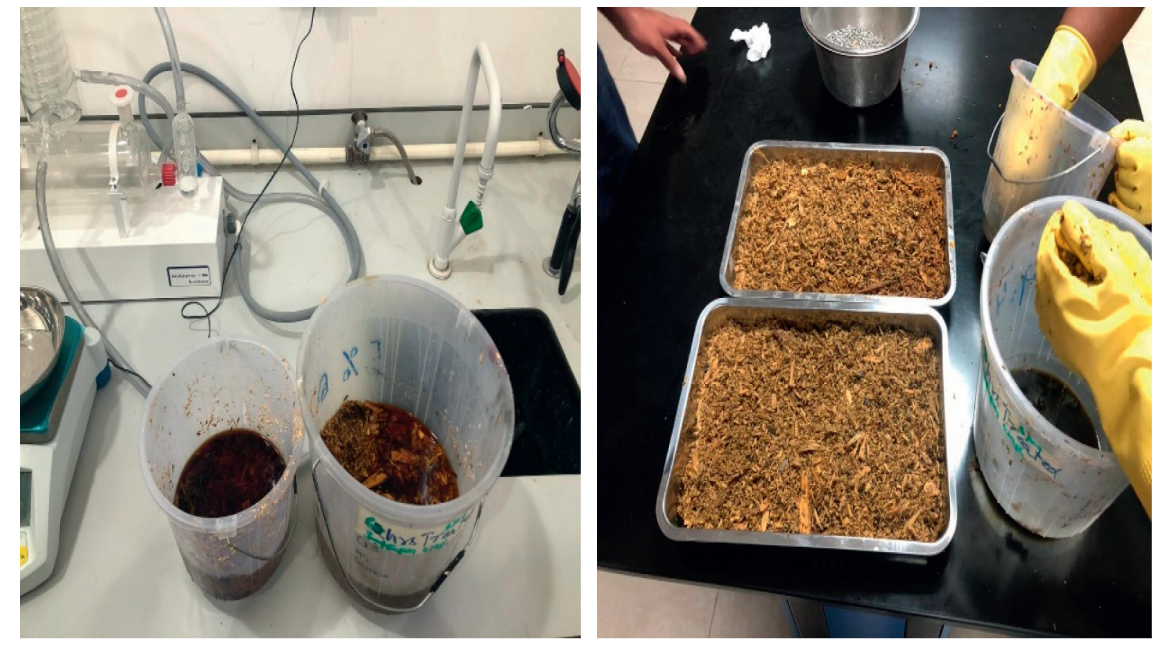

Figure 5: $\mathrm{NaOH}$ treatment of fibers.

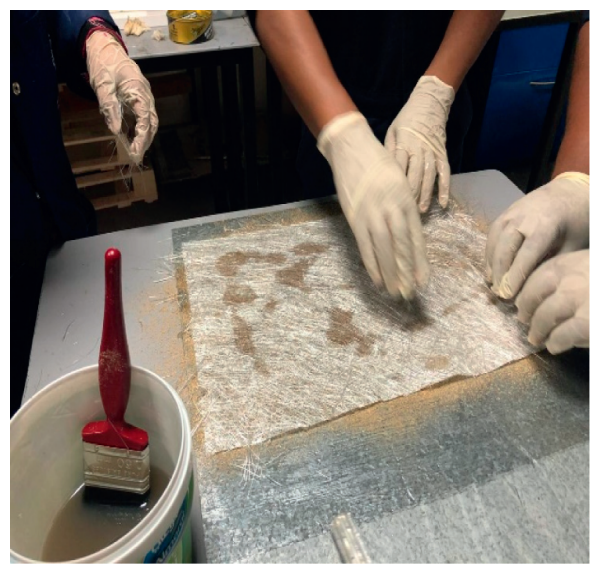

(a)

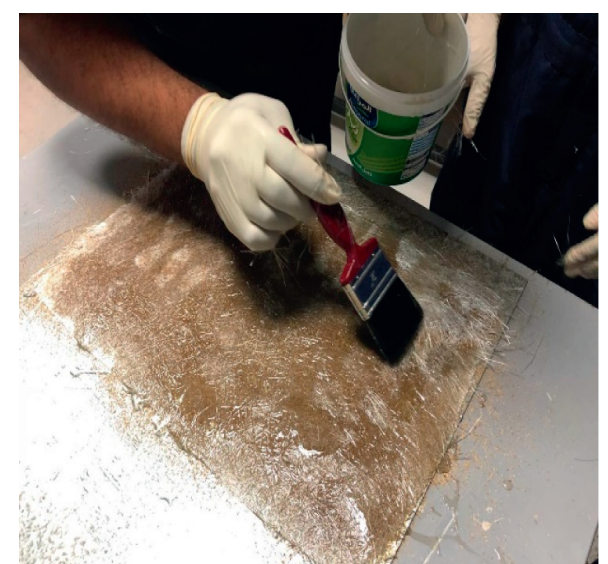

(b)

Figure 6: Continued. 


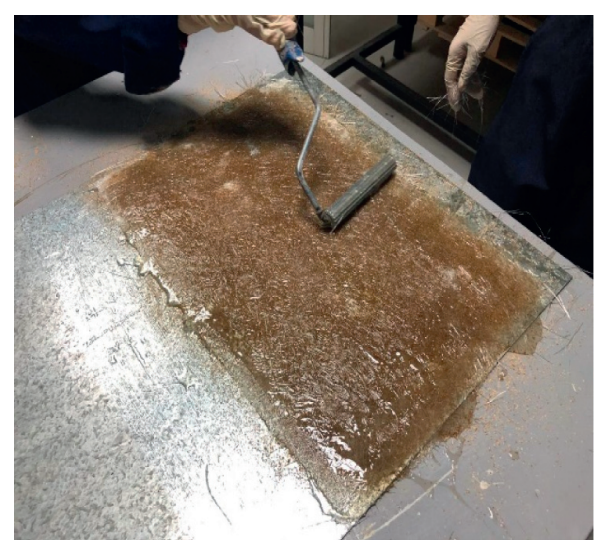

(c)

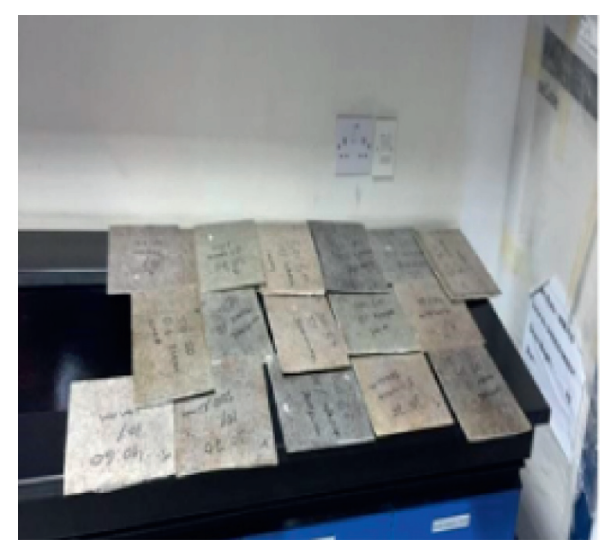

(d)

Figure 6: $(\mathrm{a}-\mathrm{c})$ Processing of composites by the hand lay technique; (d) composite laminates.

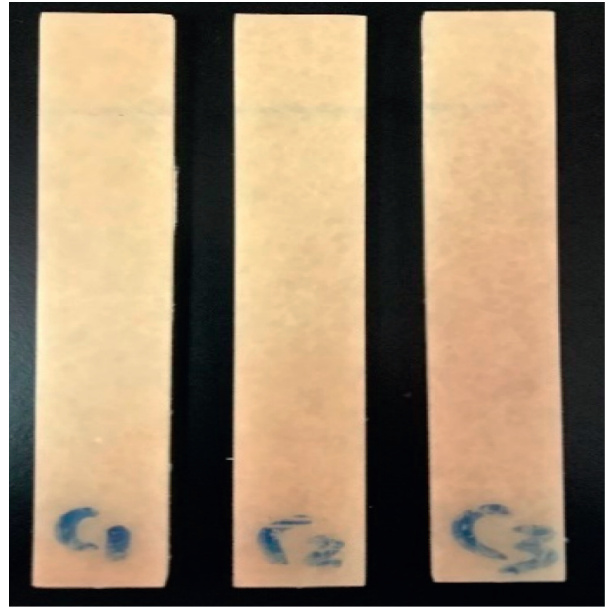

(a)

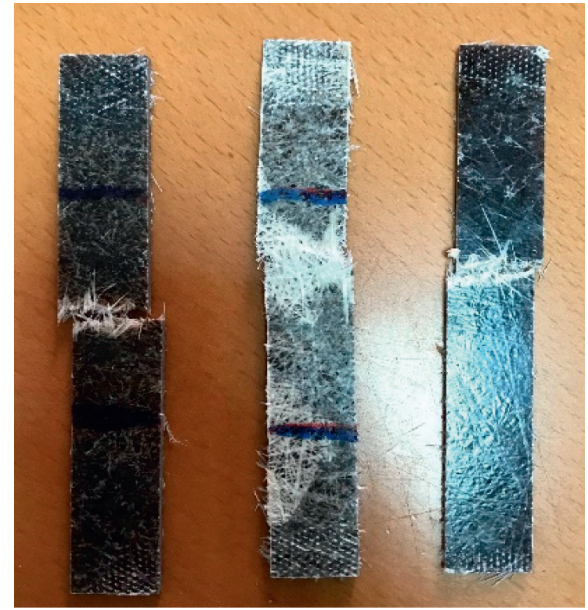

(b)

Figure 7: (a, b) Tensile specimens before and after testing.

TABLE 6: Mechanical property notations.

Tensile Strength

Bending strength

Compression strength

Shear strength

Young's modulus

TABLE 7: Overall mechanical DPF composite property results.

\begin{tabular}{|c|c|c|c|c|c|c|c|c|c|}
\hline \multirow{2}{*}{ Composite composition } & \multicolumn{5}{|c|}{ Longitudinal loading } & \multicolumn{4}{|c|}{ Transverse loading } \\
\hline & TS (MPa) & $\mathrm{BS}(\mathrm{MPa})$ & $\mathrm{C}(\mathrm{MPa})$ & $\mathrm{SS}(\mathrm{MPa})$ & $\mathrm{E}(\mathrm{GPa})$ & TS (MPa) & $\mathrm{BS}(\mathrm{MPa})$ & $\mathrm{SS}(\mathrm{MPa})$ & $\mathrm{E}(\mathrm{GPa})$ \\
\hline DPFC1 & 57.73 & 49.00 & 99.56 & 97.9 & 20.45 & 56.78 & 41.22 & 53.92 & 19.55 \\
\hline DPFC2 & 62.89 & 58.13 & 112.57 & 77.92 & 21.23 & 55.88 & 48.66 & 74.64 & 20.68 \\
\hline DPFC3 & 61.01 & 34.43 & 126.86 & 81.25 & 19.72 & 59.13 & 62.25 & 79.41 & 18.71 \\
\hline DPFC4 & 63.93 & 49.71 & 111.20 & 87.99 & 16.61 & 40.48 & 47.94 & 86.00 & 15.49 \\
\hline DPFC5 & 28.57 & 35.09 & 103.07 & 57.63 & 18.13 & 28.44 & 39.59 & 40.76 & 17.47 \\
\hline DPFC6 & 39.20 & 38.96 & 132.36 & 62.53 & 15.68 & 46.56 & 45.21 & 53.46 & 14.50 \\
\hline DPFC7 & 52.63 & 52.69 & 95.96 & 86.85 & 13.76 & 54.57 & 41.22 & 54.81 & 12.65 \\
\hline DPFC8 & 33.90 & 28.81 & 67.66 & 62.98 & 15.78 & 28.94 & 23.76 & 62.97 & 15.15 \\
\hline DPFC9 & 49.12 & 43.13 & 112.23 & 65.37 & 11.89 & 57.60 & 28.33 & 63.48 & 10.89 \\
\hline
\end{tabular}




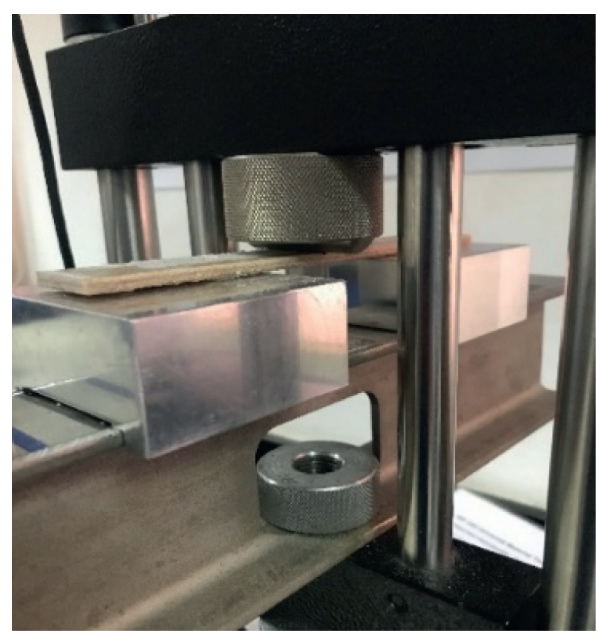

(a)

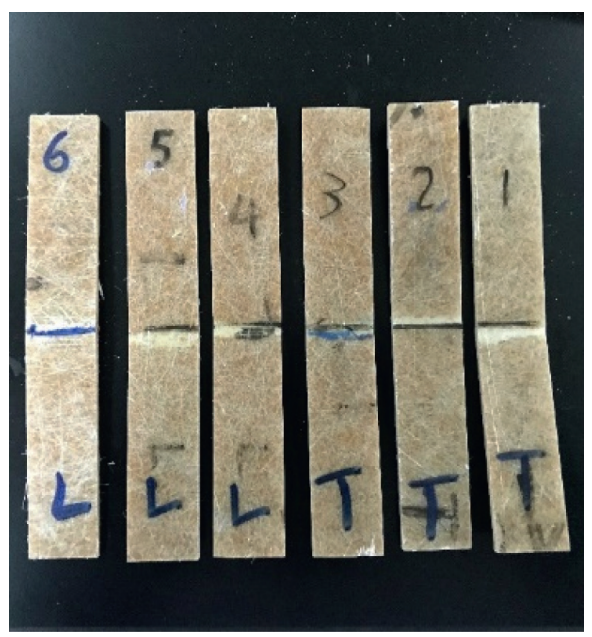

(b)

Figure 8: $(a, b)$ Flexural specimens before and after testing.

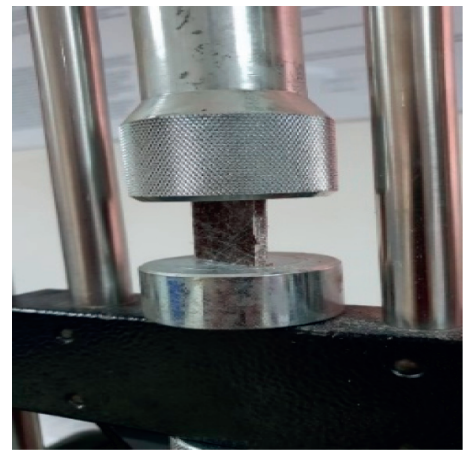

(a)

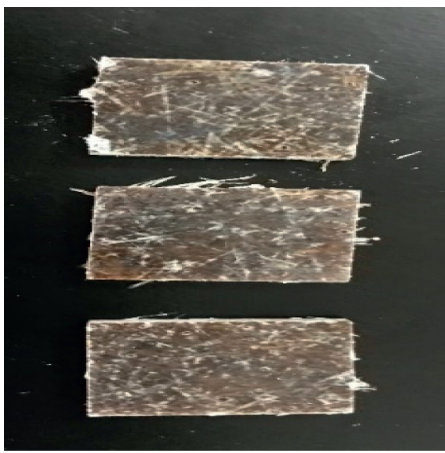

(b)

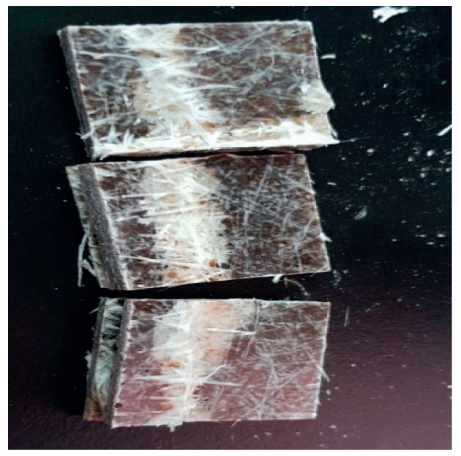

(c)

FiguRE 9: $(\mathrm{a}-\mathrm{c})$ Compression specimens before and after deformation.

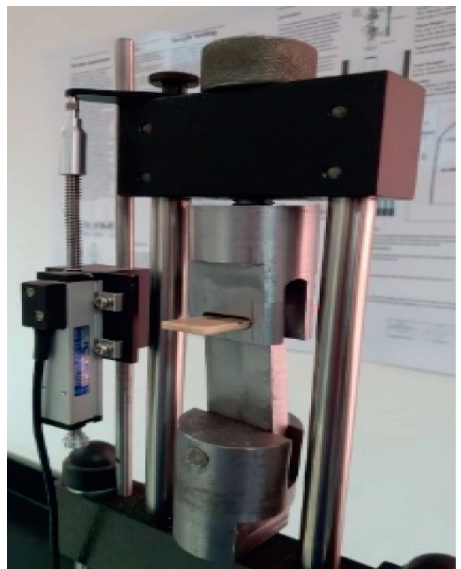

(a)

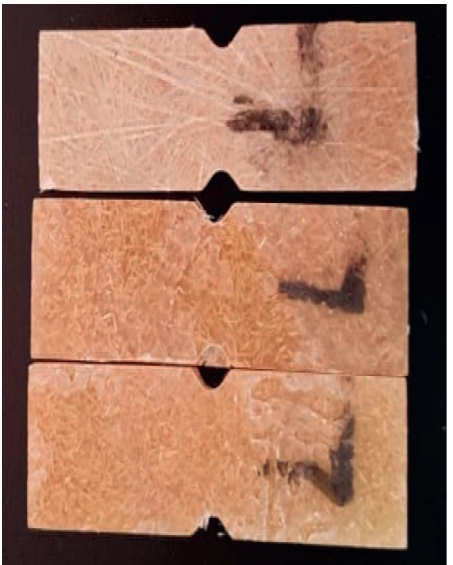

(b)

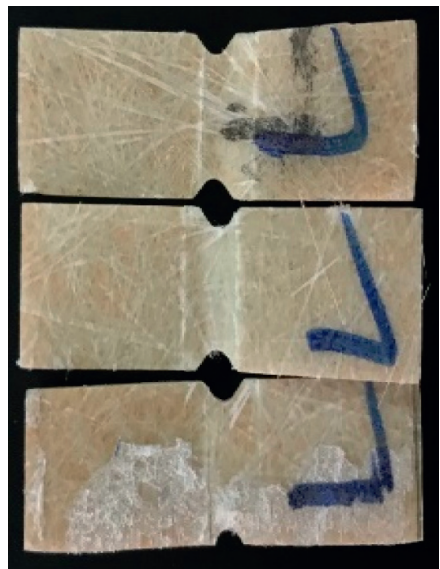

(c)

Figure 10: $(\mathrm{a}-\mathrm{c})$ Shear specimens before and after shearing. 
TABle 8: Overall mechanical coir composite property results.

\begin{tabular}{|c|c|c|c|c|c|c|c|c|c|}
\hline \multirow{2}{*}{ Composite composition } & \multicolumn{5}{|c|}{ Longitudinal loading } & \multicolumn{4}{|c|}{ Transvers loading } \\
\hline & TS (MPa) & $\mathrm{BS}(\mathrm{MPa})$ & $\mathrm{CS}(\mathrm{MPa})$ & $\mathrm{SS}(\mathrm{MPa})$ & $\mathrm{E}(\mathrm{GPa})$ & TS (MPa) & $\mathrm{BS}(\mathrm{MPa})$ & $\mathrm{SS}(\mathrm{MPa})$ & $\mathrm{E}(\mathrm{GPa})$ \\
\hline $\mathrm{CC} 1$ & 56 & 45.63 & 99.45 & 72.68 & 22.08 & 53.1 & 28.62 & 67 & 21.41 \\
\hline CC2 & 60.5 & 30.16 & 101.56 & 89.95 & 20.96 & 54.146 & 23.43 & 86.8 & 21.16 \\
\hline CC3 & 64.56 & 19.13 & 118.94 & 97.85 & 23.26 & 45.973 & 18.11 & 84.43 & 20.21 \\
\hline CC4 & 49.97 & 54.50 & 87.50 & 61.24 & 17.55 & 43.45 & 18.12 & 48.64 & 17.92 \\
\hline CC5 & 51.57 & 21.16 & 136.36 & 96 & 17.22 & 59.83 & 16.02 & 90.31 & 17.60 \\
\hline CC6 & 50.02 & 20.24 & 94.32 & 77.42 & 17.02 & 50.03 & 18.26 & 70.96 & 16.19 \\
\hline CC7 & 29.09 & 18.98 & 70.74 & 56.33 & 16.25 & 38.06 & 19.20 & 45 & 15.18 \\
\hline CC8 & 65.96 & 18.04 & 87.58 & 98.81 & 15.9 & 64.83 & 17.66 & 69.77 & 14.91 \\
\hline CC9 & 51.04 & 27.10 & 94.46 & 80.42 & 14.34 & 46.4 & 26.50 & 67.61 & 13.32 \\
\hline
\end{tabular}

TABLE 9: Properties of the pure matrix.

\begin{tabular}{lccccc}
\hline Notations & Tensile stress $(\mathrm{MPa})$ & Flexural stress $(\mathrm{MPa})$ & Compression stress $(\mathrm{MPa})$ & Shear force $(\mathrm{KN})$ & Impact strength $\left(\mathrm{J} / \mathbf{m m}^{2}\right)$ \\
\hline Pure matrix & 35.6 & 15.39 & 53.78 & 5.7 & 0.10
\end{tabular}

TABLE 10: Normal stresses, max shear stresses, and principal plane angle for DPF composite normal stresses, max shear stresses, and Von Mises stresses.

\begin{tabular}{lccccccc}
\hline $\begin{array}{l}\text { Sl. } \\
\text { no. }\end{array}$ & Composite & $\begin{array}{c}\text { Longitudinal normal } \\
\text { stress } \sigma_{\mathbf{x}}(\mathrm{MPa})\end{array}$ & $\begin{array}{c}\text { Transverse normal } \\
\text { stress } \sigma_{\mathbf{y}}(\mathrm{MPa})\end{array}$ & $\begin{array}{c}\text { Maximum shear } \\
\text { stress }(\mathrm{MPa})\end{array}$ & $\begin{array}{c}\text { Yield stress } \\
(\mathrm{MPa})\end{array}$ & $\begin{array}{c}\text { Principal plane } \\
\text { angle position }\end{array}$ & $\begin{array}{c}\text { Von Mises } \\
\text { stresses }(\mathrm{MPa})\end{array}$ \\
\hline 1 & DPFC1 & 57.73 & 56.78 & 34.35 & 57.26 & 44.6 & 57.26 \\
2 & DPFC2 & 62.89 & 55.88 & 35.8 & 59.67 & 42.2 & 60.31 \\
3 & DPFC3 & 61.013 & 59.13 & 36.1 & 60.17 & 44.3 & 60.09 \\
4 & DPFC4 & 63.93 & 40.48 & 33.4 & 55.67 & 44.7 & 55.16 \\
5 & DPFC5 & 28.573 & 28.44 & 17.1 & 28.5 & 44.9 & 28.51 \\
6 & DPFC6 & 46.565 & 39.253 & 26 & 43.33 & 49.1 & 43.37 \\
7 & DPFC7 & 54.57 & 52.63 & 32.2 & 53.67 & 45.9 & 53.63 \\
8 & DPFC8 & 33.9 & 28.94 & 19 & 31.67 & 41.3 & 31.71 \\
9 & DPFC9 & 57.6 & 49.126 & 32.3 & 53.83 & 48.8 & 53.87 \\
\hline
\end{tabular}

3.3. Density. Density is the ratio of the mass to the volume of the specimen from all the composition of the composites calculated theoretically and water displacement methods. The average values are shown in Table 4 .

$$
\begin{aligned}
\rho & =\frac{\text { mass }}{\text { volume }}=\frac{509.6}{490} \\
& =1.04 \mathrm{~g} / \mathrm{cc} .
\end{aligned}
$$

3.4. Water Absorption of Composites. Water absorption property of all composition composites was evaluated according to the ASTM D5229 standard procedure. The specimens were dried in the oven at $70^{\circ} \mathrm{C}$ until obtained constant dimensions, and they were weighed after 4 hours; then, specimens were cooled to room temperature. After weighing, the dried specimens (initial weight) had an accuracy of $0.1 \mathrm{mg}$ in the three-digit digital weighing machine. They were immersed in distilled water in a glass jar. Once in 24 hours, 48 hours, 72 hours, 86 hours, and 102 hours, the specimens were removed after every 24 hours from the jar; water from the surface was dried with a clean cloth and measured again its dimensions and weight (final weight) until no change in the mass is observed. The percentage of water absorption of these DPF and coir reinforced composites is calculated from the below-given equation. The average values are shown in Table 4 and the mechanical property notations are given below in Table 6 .

$$
\begin{aligned}
& \text { moisture absorption }=\frac{(\text { final weight }- \text { intial weight })}{(\text { initial weight })} \times 10 \\
& \text { moisture absorption }=\frac{(7.01-7.0)}{(7.0)} \times 100=0.14 \% .
\end{aligned}
$$

3.5. Theoretical Calculation for Normal Stress and Max Shear Stresses. Max shear stresses are obtained; their values are given by

$$
\begin{aligned}
\tau_{\max } & =\sqrt{\left(\frac{\sigma_{x}-\sigma_{y}}{2}\right)^{2}+\tau_{x y}{ }^{2}}=\sqrt{\left(\frac{57.73-56.78}{2}\right)^{2}+34.353^{2}} \\
& =34.356 \mathrm{MPa} .
\end{aligned}
$$

Normal stresses are obtained; their values are given by 
TABLE 11: Normal stresses, max shear stresses, and principal plane angle for coir composites.

\begin{tabular}{|c|c|c|c|c|c|c|c|}
\hline Sl. no & Composite & $\begin{array}{c}\text { Longitudinal } \\
\text { normal stress } \sigma_{\mathbf{x}}(\mathrm{MPa})\end{array}$ & $\begin{array}{c}\text { Transverse } \\
\text { normal stress } \sigma_{\mathrm{y}}(\mathrm{MPa})\end{array}$ & $\begin{array}{c}\text { Maximum } \\
\text { shear stress }(\mathrm{MPa})\end{array}$ & $\begin{array}{c}\text { Yield } \\
\text { stress (MPa) }\end{array}$ & $\begin{array}{l}\text { Principal plane } \\
\text { angle position }\end{array}$ & $\begin{array}{c}\text { Von Mises } \\
\text { stresses }(\mathrm{MPa})\end{array}$ \\
\hline 1 & $\mathrm{CC} 1$ & 56 & 53.1 & 32.762 & 54.60 & 43.732 & 54.61 \\
\hline 2 & $\mathrm{CC} 2$ & 60.5 & 53.1 & 32.938 & 54.90 & 41.775 & 57.16 \\
\hline 3 & CC3 & 64.56 & 45.973 & 35.624 & 59.37 & 47.439 & 57.56 \\
\hline 4 & $\mathrm{CC} 4$ & 49.97 & 43.45 & 28.215 & 47.03 & 41.683 & 47.05 \\
\hline 5 & CC5 & 51.57 & 59.83 & 33.674 & 56.12 & 48.522 & 56.16 \\
\hline 6 & CC6 & 50.02 & 50.03 & 30.015 & 50.03 & 45.005 & 50.03 \\
\hline 7 & CC7 & 29.096 & 38.06 & 20.64 & 34.4 & 51.271 & 34.46 \\
\hline 8 & $\mathrm{CC} 8$ & 65.96 & 64.83 & 39.241 & 65.40 & 44.588 & 65.40 \\
\hline 9 & CC9 & 51.04 & 46.4 & 29.324 & 48.87 & 42.731 & 48.89 \\
\hline
\end{tabular}

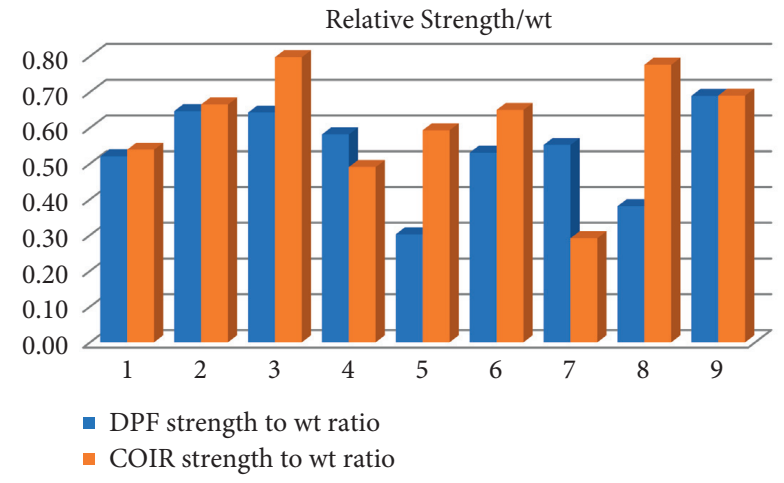

FIGURE 11: Relative strength/weight ratios of composites.

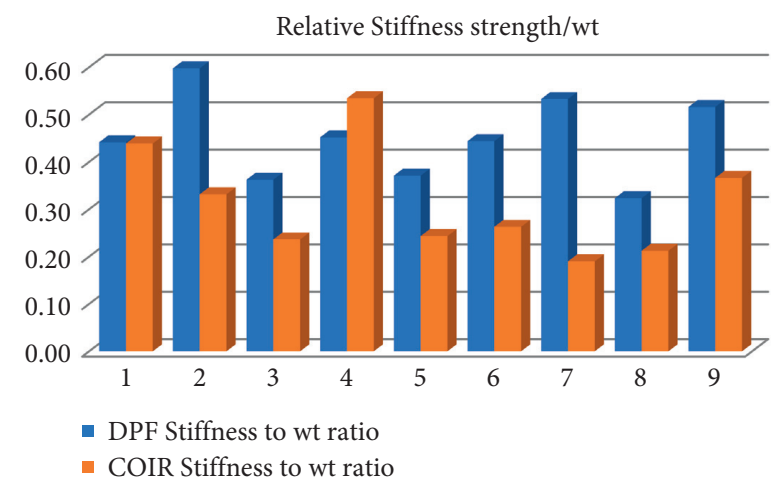

FIgURE 12: Relative stiffness strength/weight ratios of composites.

$$
\begin{aligned}
& \sigma_{1}=\left(\frac{\sigma_{x}+\sigma_{y}}{2}\right)+\tau_{\max }=\left(\frac{57.73+56.78}{2}\right)+34.356=91.61 \mathrm{MPa} \\
& \sigma_{2}=\left(\frac{\sigma_{x}+\sigma_{y}}{2}\right)-\tau_{\max }=\left(\frac{57.73+56.78}{2}\right)+34.356=22.89 \mathrm{MPa} .
\end{aligned}
$$

Location of principal plane is obtained:

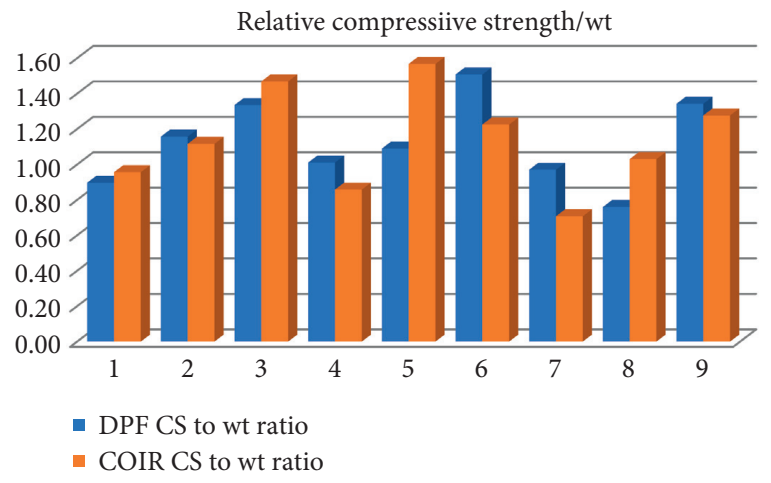

FIGURE 13: Relative compressive strength/weight ratios of composites.

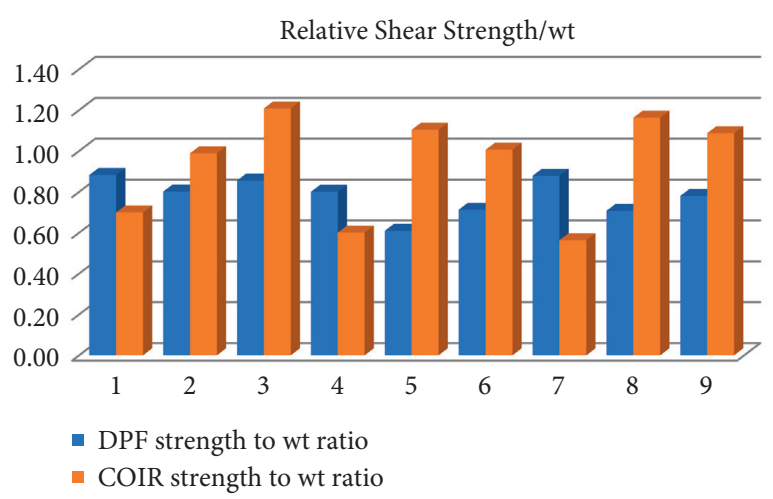

FIGURE 14: Relative shear strength/weight ratios of composites.

$$
\begin{aligned}
\operatorname{Tan} 2 \theta & =\frac{2 \tau}{\left(\sigma_{x}-\sigma_{y}\right)}=\frac{2 \times 34.356}{(57.73-56.78)} \\
2 \theta & =89.207^{\circ} \\
\theta & =44.60^{\circ} .
\end{aligned}
$$


3.6. The Distortion Energy Theory of Failure. This theory states that the Von Mises stress should be less or equal to the yield strength of the material to be considered in the safe zone.

The Von Mises stress equation is as follows:

$$
\begin{aligned}
\sigma_{\mathrm{VM}} & =\sqrt{\sigma_{1}^{2}-\sigma_{1} \sigma_{2}+\sigma_{2}^{2}} \\
\sigma_{\mathrm{VM}} & =\sqrt{57.73^{2}-(57.73 \times 56.78)+56.78^{2}} \\
& =57.26 \mathrm{MPa}, \mathrm{y}_{\mathrm{S}}=57.261 \mathrm{MPa} .
\end{aligned}
$$

$\sigma_{\mathrm{VM}}=\mathbf{y}_{\mathbf{S}}$. So, this composite sample is considered to be in the safe zone (Table 11).

\subsection{Moisture Absorption.}

3.8. Overall Specimen Mechanical Properties. Overall coir fiber composites show better strength/weight results compared to DPF fiber composites (Figure 11). 30\% wt with 5\% $\mathrm{NaOH}$ coir fiber composites and $30 \%$ wt with $10 \% \mathrm{NaOH}$ DPF fiber composites result in highest strength/weight and also same results with CCC9 (0.69).

Overall DPF fiber composites showing better stiffness/ weight results compared to coir fiber composites (Figure 12). $10 \%$ wt. with $5 \% \mathrm{NaOH} \mathrm{DPF}$ fiber composite results in highest strength/weight (0.6), whereas DPF 7 and CCC4 shows same results (0.53).

Coir fiber composites show highest compressive/weight results with marginal various with DPF fiber composites, CCC5 (1.57) and DPF 5 (1.51), Figure 13.

Overall coir fiber composites showing highest shear strength/weight results (1.21) with DPF fiber composite (0.88), Figure 14.

\section{Conclusion}

From all the above-tested results, it was found that this DPF can be molded into any shape and style. These composites have durable, good surface finish, hard not prone to shrinking (water proof), expanding or warping, having good strength, light weight with low density, insulating properties (heat resistance), cost effective, low maintenance, corrosion resistance, thermal resistance (contraction/expansion ), and it can hold wear and tear, screw support, and surface strains.

Overall coir fiber composites show better strength/ weight results compared to DPF fiber composites. 30\% wt with $5 \% \mathrm{NaOH}$ coir fiber composites and $30 \%$ wt with $10 \%$ $\mathrm{NaOH}$ DPF fiber composites result in highest strength/ weight.

Overall DPF fiber composites show better stiffness/ weight results compared to coir fiber composites. $10 \% \mathrm{wt}$. with $5 \% \mathrm{NaOH}$ DPF fiber composites results in highest strength/weight (0.6) whereas DPF 7 and CCC4 show same results $(0.53)$.

Coir fiber composites show highest compressive/weight results with marginal variety with DPF fiber composite.
Overall coir fiber composites show highest shear strength/weight results (1.21) with the DPF fiber composite (0.88).

Hence, this DPF material can replace a few conventional materials such as wood, plastics, and aluminum and can be used in the following applications in construction interiors such as electronic components, furniture, sports, and automotive industries.

\section{Data Availability}

The data used to support the findings of this study are included in the article.

\section{Disclosure}

This research was performed as a part of the Employment Hawassa University, Ethiopia.

\section{Conflicts of Interest}

The authors declare that there are no conflicts of interest regarding the publication of this paper.

\section{Acknowledgments}

The authors appreciate the technical assistance to complete this experimental work from the Department of Mechanical Engineering, K.Ramakrishnan college of Engineering, Trichy, Tamilnadu, India.

\section{References}

[1] C. Obele and E. Ishidi, "Mechanical Properties of coir fiber reinforced epoxy resin composites for helmet shell," Industrial Engineering Letters, vol. 5, 2015.

[2] A. E. Elsayed, H. Hiroyuki, and S. A. Mohamed, "Mechanical properties of natural jute fabric/jute Mat fiber ReinforcedPolymer matrix hybrid composites," Advances in Mechanical Engineering, vol. 4, 2012.

[3] M. K. Marichelvam, P. Manimaran, A. Verma, M. R. Sanjay, and K. K. M. Geetha, "A Novel palm Sheath and Sugarcane Bagasse Fiber Based Hybrid Composites for Automotive Applications: An Experimental approach," Polymercomposites, Wiley online Library, Hoboken, NJ, USA, 2020.

[4] H. Ku, H. Wang, N. Pattarachaiyakoop, and M. Trada, "A review on the tensile properties of natural fiber reinforced polymer composites," Composites Part B: Engineering, vol. 42, no. 4, pp. 856-873, 2011.

[5] A. Verma and V. K. Singh, Journal of Testing and Evaluation, vol. 47, p. 1193, 2019.

[6] R. Potluri, "Natural fiber-based hybrid bio-composites: processing, characterization, and applications," in Green ComPosites, S. Muthu, Ed., Springer, Heidelberg, Germany, pp. 1-46, 2019.

[7] C. Dong, "Review of natural fibre-reinforced hybrid composites," Journal of Reinforced Plastics and Composites, vol. 37, p. 331, 2018.

[8] B. Neher, M. M. R. Bhuiyan, H. Kabir, M. R. Qadir, M. A. Gafur, and F. Ahmed, "Study of mechanical and physical properties of palm fiber reinforced acrylonitrile 
butadiene styrene composite," Materials Sciences and Applications, vol. 5, no. 1, pp. 39-45, 2014.

[9] V. Arumuga Prabu, V. Manikandan, R. Venkatesh et al., "AIMS AND SCOPE," Materials Physics and Mechanics, vol. 24, p. 41, 2015.

[10] A. K. Rout, J. Kar, D. K. Jesti, and A. K. Sutar, "Industrial Biorefineries \& White Biotechnology," Bioresources, vol. 11, p. 4432, 2016.

[11] K. N. Bharath, P. Madhu, T. G. Y. Gowda, and A. Verma, M. R. Sanjay and S. Siengchin, A Novel Approach for Development of Printed Circuit Board from Biofiber Based composites," Polymercomposites, Wiley online, Hoboken, NJ, USA, 2020.

[12] N. Jain, AkarshVerma, and V. K. Singh, "“Dynamic mechanical analysis and creep-recovery behaviour of polyvinyl alcohol based cross-linked biocomposite reinforced with basalt fiber" materials," Research Express, vol. 6, no. 10, 2019.

[13] U. K. Essays, Natural vs. synthetic fiber reinforced polymer, 2013.

[14] L. Ghali, S. Msahli, M. Zidi, and F. Sakli, "Effects of fiber weight ratio, structure and fiber modification onto flexural properties of luffa-polyester composites," Advances in Materials Physics and Chemistry, vol. 1, no. 3, pp. 78-85, 2011. 